\title{
Epidemiology of fractures in Children at College of Medical Sciences and Teaching Hospital, Bharatpur, Nepal
}

Gupta HK Lecturer, Department of Orthopaedics, College of Medical Sciences and Teaching Hospital, Bharatpur, Chitwan, Nepal.

\begin{abstract}
\section{Objective}

To study the epidemiology of fractures in the pediatric population.

\section{Methods}

All the cases of fractures of age 14 yrs or less presenting in emergency room or outdoor patient department of Orthopaedics during the time period of January 2013 to December 2013 were included in the study and prospectively studied. Demographic data were collected and analysed by descriptive methods.
\end{abstract}

\section{Results}

The incidence of fracture was more in male child. Most fractures occurred in age group of 6 to 14 years. Lower limb fractures (56.8\%) were more common than upper limb fractures. Incidence of injuries was more during summer most common mode of trauma being motor vehicle accidents (26\%).

\section{Conclusion}

Proper supervision and guidance during outdoor activities, on the play ground and proper home safety measures with improved road conditions and proper traffic knowledge can markedly reduce the incidence of pediatric trauma.

Key words: Pediatric fracture, Motor vehicle accident (MVA), sports injuries.

\section{INTRODUCTION}

Trauma is an important cause of disability, hospitalization and even death in pediatric population. It has a huge social and economical impact on the society in the developing country like ours. Trauma has been attributed to be leading cause of death in

Correspondence: Dr. H.K. Gupta

E-mail:hmntkg@yahoo.com children in USA accounting for 50\% of deaths after first year of life. ${ }^{1}$ Around one-third of all children suffer at least one fracture before the age of 17 years, ${ }^{2}$ and the fractures are $9 \%$ of all kinds of injuries in children getting medical treatment. ${ }^{3}$ There is a continuous rise in the cases of road traffic accidents. The children are prone to have inury even at play grounds and due to fall because of the geographical reasons in our part of world. 
Journal of College of Medical Sciences-Nepal, 2014, Vol-10, No-1

There is very limited data on epidemiology of fractures in paediatric population in our country. The aim of this study is to determine the pattern of fractures in the paediatric population.

\section{METHODS}

This study was conducted at College of Medical Sciences and Teaching Hospital, Bharatpur, a tertiary referral center in central Nepal during the time period of January 2013 to December 2013. All the cases of fractures of age 14 yrs or less presenting in emergency room or outdoor patient department of Orthopaedics were included in the study. Demographic data like age, sex, mode of injury, time of injury and injured site were recorded. The treatment of all these patients were commenced accordingly and treated at our institute. Descriptive statistics were used to analyze the data.

\section{RESULTS}

Over the period of one year, 250 patients with fractures and dislocations of pediatric age group were treated at our hospital. Among them 195(78\%) were boys and $55(22 \%)$ girls. Most of the cases were observed during the months of April, May and June, total of 95 $\operatorname{cases}(38 \%)$. Least cases were seen in the months of January, February and March, total of only 40 $\operatorname{cases}(16 \%)$. 60 cases (24\%) were seen in the months of July, August and September , and $55 \operatorname{cases}(22 \%)$ of total were seen in the months of October, November and December. The modes of injuries have been summarized in table 1. Motor vehicle accident (MVA) is alone responsible for maximum number of cases of fractures ( $n=65)$. Following MVA, fall from height is second major cause of fractures in children $(n=34)$, other causes were fall at home due to trivial injury, fall from bicycle and sports related. In our study lower limb fractures were more common (56.8\%), followed by upper limb fractures (42\%). During the period of the study, only one case of spinal injury and two cases of pelvic fractures were seen, these injuries were sustained in high velocity MVA(Table 2 ).

As per table 3, we can observe that the fractures were more common in the age group of 6 to 14 years and fall from height was the major mode of injury. In the age of 3 to 6 years, MVA and fall injury at home were the major modes of injury. In the age group of 0 to 2 years, only two cases were observed, one sustained injury in MVA and another at home due to fall from bed.

Table 1: Causes of injuries.

\begin{tabular}{ll} 
Mode of injury & Number (percent) \\
\hline Motor vehicle accident & $65(26)$ \\
Pedestrians & $34(13.6)$ \\
Sports related & $25(10)$ \\
Fall from height & $56(22.4)$ \\
Fall at home & $21(8.4)$ \\
School & $20(8)$ \\
Cycle & $29(11.6)$ \\
Total & $250(100)$
\end{tabular}

Table 2. Site of fractures

\begin{tabular}{|ll} 
Site of fractures & Number (percent) \\
\hline Upper limb & $105(42)$ \\
Lower limb & $142(56.8)$ \\
Spine & $1(0.4)$ \\
Pelvis & $2(0.8)$ \\
\hline Total & $250(100)$ \\
\hline
\end{tabular}


Gupta HK Epidemiology of fractures..........

\section{Table 3. Relation of trauma among different age groups}

\begin{tabular}{ccccccccc}
$\begin{array}{c}\text { AGE group } \\
(\mathbf{y r s})\end{array}$ & $\begin{array}{c}\text { No. of } \\
\text { fractures }\end{array}$ & MVA & Pedestrian & Sports & Fall & Home & School & cycle \\
\hline $0-2$ & 2 & 1 & 0 & 0 & 0 & 1 & 0 & 0 \\
$3-6$ & 49 & 19 & 2 & 3 & 4 & 11 & 3 & 7 \\
$6-14$ & 199 & 45 & 32 & 22 & 52 & 9 & 17 & 22 \\
Total & $\mathbf{2 5 0}$ & $\mathbf{6 5}$ & $\mathbf{3 4}$ & $\mathbf{2 5}$ & $\mathbf{5 6}$ & $\mathbf{2 1}$ & $\mathbf{2 0}$ & $\mathbf{2 9}$ \\
\hline
\end{tabular}

\section{Discussion}

In this study we found that MVA was an important cause of fractures in children. It has been shown in other studies also that road traffic accidents were the major cause of pediatric trauma ${ }^{4}$. Boys were more affected than girls. Valerio et. $\mathrm{al}^{5}$ had also found that boys had more fractures than girls. According to his study domestic injuries were the most common cause of pediatric fractures. In our study, domestic injuries accounted only for $8.4 \%$ of pediatric fractures. MVA might have increased due to increased numbers of vehicles and drivers in our part of the world. When there is increase in number of vehicles on the road, the risk of pedestrian injury also increases proportionately. It is not uncommon to see that the children playing on the road, moving on the road unsupervised and also the lack of traffic knowledge. Lower limb fractures were more common in our study and in other studies as well ${ }^{6}$. In the age group of 6 to 14 years, peak of injuries were seen, in some studies a bimodal peak was found at age 5 and 8 years ${ }^{7}$, and other studies shows early peak in 5 and 6 years and later peak in adolescent ${ }^{8}$. Seasonal variations were seen in the study; more common in the month of April, May and June (38\%), followed by $24 \%$ in July, August and September and least in the winter season. These variations can be described with social and cultural reasons in Nepal where people travel more, celebrate and holidays at school. At this time there are more instances of fall from swing tree and playground injuries. According to Rockwood \& Wilkins ${ }^{9}$ the average number of fractures in summer is 2.5 times more than in winter. Fractures sustained in the school area (8\%) are mainly concerned with the school administration. Almost each family in our part of world owns a bicycle hence bicycle related injuries are also not uncommon, in our study it was $11.6 \%$. Sports related fractures were seen more in the age group of 6 to 14 years $(10 \%)$, may be this is the age group where the children go out for outdoor activities. Sports accounted for more fractures in the studies by Landin ${ }^{10}$, Tiderius et. al. ${ }^{11}$ and Reni et. al. ${ }^{8}$

\section{CONCLUSION}

Pediatric fractures are a major concern since they impose a great social, economical and psychological impact on our community. In the country like ours with more of lower and middle socio economic group of families, poverty and illiteracy prevails and the problem increases exponentially. Although the fracture healing in pediatric age group is very good and have 
Journal of College of Medical Sciences-Nepal, 2014, Vol-10, No-1

been studied since early forties and fifties ${ }^{12}$, our aim should be towards decreasing the incidence of pediatric fractures. Proper education and information, knowledge of the traffic, road management with proper pedestrian's pathway and zebra crossings are the preventive measures to be reinforced upon. In the pediatric age group, proper supervision and guidance during outdoor activities on the play ground and proper home safety measures are other important things to be taken care of. Pediatric fractures, most of the times, are potentially quite a lot preventable.

\section{REFERENCES}

1. Rockwood CA, Wilkins KE, King RE, editors. Fractures in children. Philadelphia: JB Lippincott; 1984.

2. Cooper C, Dennison EM, Leufkens HG, et al. Epidemiol-ogy of childhood fractures in Britain: a study using the general practice research database. J Bone Miner Res 2004;19:1976-81.

3. Spady DW, Saunders DL, Schopflocher DP, et al. Patterns of injury in children. Pediatrics 2004;113:522-9.

4. Reed MH. Fractures and dislocations of the extremities in children. J Trauma 1977;17:351-4.
5. Valerio G, Gallè F, Mancusi C, et al. Pattern of fractures across pediatric age groups:Analysis of individual and lifestyle factors. BMC Public Health 2010;10:656.

6. Alomran AK, Bubshait DA, Sadat-Ali M. Epidemiology of paediatric fractures and dislocations; analysis in patients. Bahrain Med Bulletin 2012;34(4).

7. Tripathi RB, Sah RP, Ali R et al. Clinico epidemiological study on Paediatric at Narayani Sub Regional Hospital, Birgunj. Journal of GMCNepal 2009; 2(2):39-44.

8. Rennie L, Court-Brown CM, Mok J, et al. The epidemiology of fractures in children. Injury 2007;38: 913-22.

9. Rockwood \& Wilkin's Fracture In Children. 2006, $6^{\text {th }}$ Ed.Lippincott Williams \& Williams.

10. Landin LA. Epidemiology of children's fractures. J Pediatr Orthop 1997; 6: 79-83.

11. Tiderius CJ, Landin L A, Duppe H. Decreasing Incidence of fractures in children: an epidemiological analysis of 1,673 fractures in Malmö Sweden 1993-94. Acta Orthop Scand 1999;70:622-6.

12. Beckmann F, Sultan J E. Some observations on fractures of long bones in children. Am J Surg 1941:51:722 